Original Research Paper

\title{
Respon Stek Pucuk Tanaman Miana (Coleus atropurpureus (L.) Benth) terhadap Pemberian Zat Pengatur Tumbuh
}

\author{
Eltis Panca Ningsih ${ }^{1 *}$, Imas Rohmawati ${ }^{2}$ \\ ${ }^{1,2}$ Program Studi Agroekoteknologi, Fakultas Pertanian, Universitas Sultan Ageng Tirtayasa, Banten, Indonesia
}

\section{Article history}

Received : 27 Juni 2019

Revised : 27 September 2019

Accepted : 7 Oktober 2019

Published : 7 November 2019

*Corresponding Author:

Eltis Panca Ningsih

Program Studi

Agroekoteknologi, Fakultas

Pertanian, Universitas Sultan

Ageng Tirtayasa, Banten,

Indonesia;

Email:eltispn14@gmail.com
Abstrak : Tanaman miana saat ini dimanfaatkan sebagai tanaman hias. Perbanyakan Tanaman miana dapat dilakukan dengan cara generatif maupun vegetatif. Stek pucuk merupakan cara perbanyakan vegetatif tanaman miana yang relatif mudah dilakukan. Pembibitan dengan cara ini merupakan salah satu cara cepat dalam memenuhi kebutuhan bahan tanaman skala besar. Penelitian ini bertujuan untuk mengetahui pengaruh pemberian Zat Pengatur Tumbuh terhadap stek pucuk tanaman miana (Coleus atropurpureus (L.) Benth. Penelitian dilaksanakan di di laboratorium agroekologi, Fakultas Pertanian, Universitas Sultan Ageng Tirtyasa. Penelitian akan dilaksanakan pada bulan pada bulan Maret sampai Mei 2017. Penelitian ini menggunakan Rancangan Acak Kelompok (RAK) yang yang terdiri dari empat perlakuan dan diulang tiga kali. Perlakuan yang diuji dalam percobaan ini adalah: kontrol (Tanpa ZPT), IAA 750 ppm, Growtone 500 ppm, dan air kelapa $10 \%$. Hasil penelitian menunjukkan bahwa pemberian zat pengatur tumbuh berpengaruh terhadap jumlah tunas dan jumlah akar. Jumlah tunas terbanyak terdapat pada perlakuan Growtone sebesar 7.50 tunas. Jumlah akar terbanyak terdapat pada perlakuan IAA sebesar 91.00 buah. Rekomendasi budidaya tanaman miana dengan cara stek dapat menggunakan IAA 750 ppm maupun Growtone 500 ppm.

Kata Kunci : miana, stek, zat pengatur tumbuh

Abstract : Miana plant is currently used as an ornamental plant. The multiplication of miana crops can be done in a generative and vegetative way. Cuttings is a vegetative way of reproduction of miana plant which is relatively easy to do. Breeding in this way is one of the quick ways in meeting the needs of large-scale plant materials. This research aims to determine the effect of giving Plant Growth Regulator to the shoots cuttings of Miana (Coleus atropurpureus (L.) Benth). Research conducted in the Agroecological laboratory, Faculty of Agriculture, University of Sultan Ageng Tirtyasa. The research will be held in the month of March to May 2017. The study conducted by randomized block design (RBD) which consists of four treatments and is repeated three times. The treatment tested in this experiment was: control (without plant growth regulator), IAA $750 \mathrm{ppm}$, Growtone 500 ppm, and $10 \%$ coconut water. The results showed that the treatment of plant growth regulator affected in the number of shoots and the number of roots. The most number of shoots is in the Growtone treatment of 7.50 shoots. The highest number of roots is in the IAA treatment of 91.00 pieces. Recommendations for cultivation of miana crops with cuttings can use IAA 750 ppm maupun Growtone 500 ppm.

Keyword : Miana, cuttings, growing regulatory substances 


\section{Pendahuluan}

Tanaman miana sering disebut sebagai tanaman iler atau jawer kotok. Tanaman miana saat ini dimanfaatkan sebagai tanaman hias di taman-taman kota. Daun tanaman ini sangat beragam dan atraktif. Selain memiliki warna yang beragam dan atraktif, daun tanaman miana berkhasiat sebagai obat beberapa penyakit dan bermanfaat untuk kesehatan. Tanaman miana termasuk dalam famili Lamiaceae (DPKP Malangkota, 2017). Tanaman miana telah banyak dimanfaatkan oleh masyarakat Indonesia antara lain sebagai bahan obat (Bawoleh et al., 2017), pelengkap ritual (Suswita et al., 2013) dan tanaman hias (Haryati et al., 2015). Daun miana memiliki berbagai macam khasiat sebagai obat hepatitis, menurunkan demam, batuk, influenza, penetralisir racun, antiseptik dan lain-lain. Bagian tanaman yang digunakan sebagai obat adalah bagian daun. Daun Miana ini mengandung minyak atsiri, antara lain karvakrol yang bersifat antibakteri, eugenol bersifat menghilangkan nyeri, etil salisilat menghambat iritasi (Pakadang, 2015).

Perbanyakan Tanaman miana dapat dilakukan dengan cara generatif maupun vegetatif. Upaya perbanyakan secara vegetatif dapat dilakukan dengan beberapa cara yaitu stek, cangkok, dan okulasi. Bahan tanam yang digunakan dalam perbanyakan stek dapat menggunakan di antaranya cabang, pucuk, akar, dan daun (Hartman et al., 2002). Perbanyakan tanaman miana menjadi upaya yang perlu dilakukan dalam usaha pembudidayaan. Stek pucuk merupakan cara perbanyakan tanaman yang relatif mudah dilakukan. Pembibitan dengan cara ini merupakan salah satu cara cepat dalam memenuhi kebutuhan bahan tanaman skala besar. Namun dalam proses produksi diperlukan media tanam dan juga zat pengatur tumbuh yang tepat untuk memperoleh kualitas bibit yang baik. Zat Pengatur Tumbuh adalah senyawa organik bukan hara, yang dalam jumlah sedikit (l $\mathrm{mM})$ dapat merangsang, menghambat dan mempengaruhi pola pertumbuhan dan perkembangan tanaman (Wattimena, 2000).

Pada fase pembibitan dengan metode stek, faktor yang mempengaruhi tingkat keberhasilan stek yaitu hormon tumbuh yang dapat menginduksi pembentukan akar dan tunas (Hartmann, Kester and Davies, 1990). Berdasarkan sumbernya, ZPT dapat diperoleh baik secara alami maupun sintetik. Umumnya ZPT alami langsung tersedia di alam dan berasal dari bahan organik, contohnya air kelapa, urin sapi, dan ekstraksi dari bagian tanaman (Shahab et al., 2009; Zhao 2010). IAA merupakan zat pengatur tumbuh yang tergolong dalam auksin yang berfungsi peran dalam pembesaran sel, dapat menghambat pertumbuhan tunas samping, berperan dalam pembentukkan jaringan xilem serta floem, dan juga memiliki pengaruh terhadap perkembangan dan pemanjangan akar (Wattimena, 1988). Pemberian IAA konsentrasi 100 ppm mampu menghasilkan pertumbuhan akar yang lebih baik pada Jati (Tectona grandis Linn. f.) (Uanikrishnan dan Rajeeve, 1990). Lingga (1986) mengemukakan Growtone adalah hormon tumbuhan berbentuk bubuk berwarna abu-abu yang gunanya untuk merangsang pertumbuhan akar (stum, setek, cangkok). Penelitian ini bertujuan untuk mengetahui pengaruh pemberian Zat Pengatur Tumbuh terhadap stek pucuk tanaman miana (Coleus atropurpureus (L.) Benth.

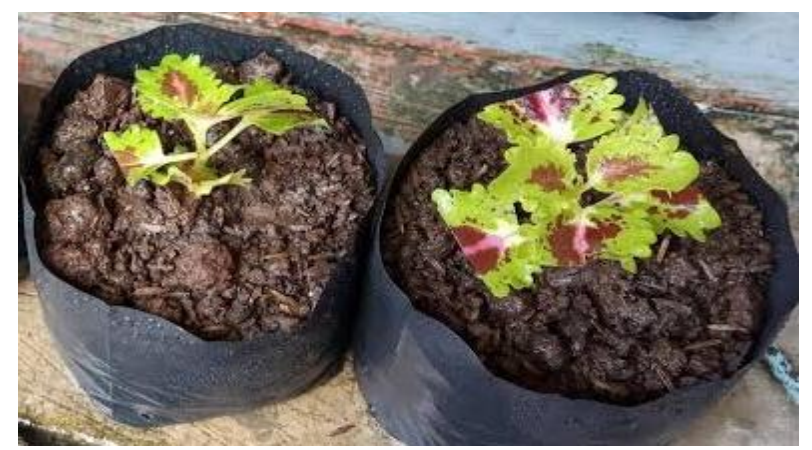

Gambar 1. Stek pucuk tanaman miana

\section{Bahan dan Metode}

\section{Lokasi dan Waktu Penelitian}

Penelitian dilaksanakan di laboratorium agroekologi, Fakultas Pertanian, Universitas Sultan Ageng Tirtyasa. Penelitian dilaksanakan pada bulan pada bulan Maret sampai Mei 2017.

\section{Alat dan Bahan Penelitian}

Bahan yang digunakan dalam percobaan ini adalah bahan stek dari tanaman miana dengan pucuk yang digunakan memiliki 3-5 daun, IAA, Rootone-F, air kelapa, campuran arang sekam: kompos dengan perbandingan 1: 1. Alat-alat yang dipergunakan yaitu cutting/pisau, nampan, label, timbangan analitik dan meteran.

\section{Metode Penelitian}

Penelitian ini menggunakan Rancangan Acak Kelompok (RAK) yang yang terdiri dari empat perlakuan dan diulang tiga kali. Perlakuan yang diuji dalam percobaan ini adalah: kontrol (Tanpa ZPT), IAA 750 ppm, Growtone 500 ppm, dan air kelapa $10 \%$.

Tahapan pelaksanaan penelitian ini adalah: (1) menyiapkan media tanam campuran arang sekam: kompos dengan perbandingan 1: 1 di nampan, (2) bahan stek dari tanaman miana dilakukan dengan cara 
memotong pucuk tanaman miana yang memiliki 3-5 daun, (3) Kemudian stek direndam selama 30 menit sesuai dengan perlakuan IAA 750 ppm, Growtone 500 ppm, dan air kelapa 10\%, (4) menanam stek pada media tanam. Parameter yang diamati meliputi persentase setek tumbuh, jumlah tunas, panjang akar dan jumlah akar.

Data dianalisis dengan sidik ragam, sidik ragam yang nyata dilanjutkan dengan menggunakan UjiJarak Berganda Duncan dengan taraf $\alpha=5 \%$.

\section{Hasil dan Pembahasan}

\section{Persentase Stek Tumbuh}

Pada Gambar 1 menunjukkan persentase setek hidup $(100 \%)$ terdapat pada seluruh perlakuan pada stek miana. Hal ini disebabkan tanaman miana memiliki batang herba sehingga dapat dikembang biakan dengan stek, sehingga memudahkan dalam perbanyakan penanaman. Tanaman miana merupakan tanaman berkayu lunak dan memiliki daya regenerasi yang tinggi. Menurut Wudianto (2001) stek batang berkayu lunak (softwood cutting) lebih mudah berakar dibanding stek batang berkayu keras (hardwood cutting) pada kondisi yang optimum. Hartmann (1990) menyatakan bahwa perbanyakan dengan stek dapat dilakukan dengan menggunakan bagian batang, akar dan daun tanaman yang dipotong dari tanaman induk. Bagian-bagian tanaman tersebut memiliki respon yang berbeda-beda terhadap penyetekan. Stek yang diambil dari bagian ujung batang dapat memberikan respon yang berbeda dari stek yang diambil dari bagian pangkalnya. Perbedaan respon dari tiap bagian tanaman tersebut dipengaruhi oleh perbedaan kandungan cadangan makanan yang terkandung dalam tanaman terutama untuk unsur nitrogen dan karbohidrat. Persediaan nitrogen dan karbohidrat.yang cukup mampu membantu proses pembentukan akar dan tunas pada bahan stek Persentase stek tumbuh pada berbagai perlakuan zat pengatur tumbuh disajikan pada Gambar 1 .

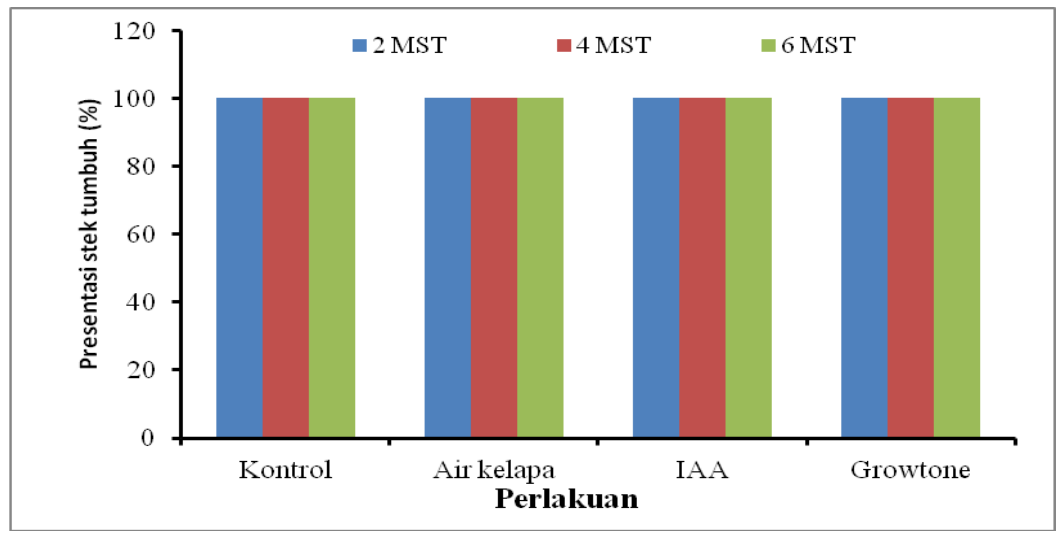

Gambar 1. Persentase stek tumbuh pada berbagai perlakuan Zat Pengatur Tumbuh

\section{Jumlah Tunas}

Pada Tabel 1 dapat dilihat bahwa pemberian zat pengatur tumbuh berpengaruh nyata pada jumlah tunas. Jumlah tunas terendah pada 6 minggu setelah tanam (MST) sebesar 3.00 tunas didapat dari perlakuan kontrol sedangkan jumlah tunas terbanyak didapat dari pemberian Growtone sebesar 7.50 tunas. Hal ini diduga karena konsentrasi Growtone dengan konsentrasi yang sesuai dapat merangsang pembentukan tunas pada tanaman miana secara maksimal. Menurut Hidayat (2010) bahwa Growtone, sejenis dengan Rotone-F, yang memiliki kandungan bahan aktif antara lain: 1 Naphthaleneacematide $(0,06 \%), 2$ - Methyl - 1 Naphthaleneacetic Acid (0,033 \%), 3 - Methyl - 1 Naphthaleneacematide $(0,013 \%)$, Indole - 3 - Butiryc Acid $(0,057 \%)$ dan Thiram (Tetramethyl thiuram disulfida) (4,000 \%). Growtone berperan dalam merangsang pembentukan akar dan tunas. Pengaruh berbagai zat pengatur tumbuh pada jumlah tunas tanaman miana disajikan pada Tabel 1 
Tabel 1. Pengaruh berbagai zat pengatur tumbuh pada jumlah tunas tanaman miana (tunas)

\begin{tabular}{llcc}
\hline \multicolumn{1}{c}{ Perlakuan } & $2 \mathrm{MST}$ & $4 \mathrm{MST}$ & $6 \mathrm{MST}$ \\
\hline Kontrol & $1.50 \mathrm{~b}$ & $3.00 \mathrm{a}$ & $3.00 \mathrm{~b}$ \\
Air Kelapa & $3.00 \mathrm{ab}$ & $4.00 \mathrm{a}$ & $7.00 \mathrm{a}$ \\
IAA & $3.50 \mathrm{a}$ & $3.50 \mathrm{a}$ & $4.00 \mathrm{ab}$ \\
Growtone & $3.50 \mathrm{a}$ & $4.50 \mathrm{a}$ & $7.50 \mathrm{a}$ \\
\hline
\end{tabular}

Keterangan : Angka yang diikuti notasi yang sama pada setiap kolom yang sama menunjukkan berbeda tidak nyata menurut Uji Jarak Berganda Duncan pada taraf $\alpha=5 \%$.

\section{Panjang Akar dan Jumlah Akar}

Pada Tabel 2 dapat dilihat bahwa pemberian zat pengatur tumbuh tidak memberikan pengaruh pada panjang akar. Panjang akar terendah pada 6 MST sebesar $14.00 \mathrm{~cm}$ didapat dari pemberian IAA sedangkan panjang akar tertinggi didapat dari perlakuan kontrol sebesar $21.08 \mathrm{~cm}$. Hal ini diduga karena ZPT eksogen yang yang diberikan tidak berpengaruh terhadap panjang akar. Menurut Harsanto (1997) bahwa jika di dalam bahan stek sudah cukup terdapat ZPT endogen, maka penambahan ZPT eksogen tidak diperlukan. Sebaliknya, jika bahan stek berada dalam kondisi kurang ZPT endogen, maka keberhasilan penyetekan sangat ditentukan oleh penambahan ZPT eksogen. Pengaruh berbagai zat pengatur tumbuh pada panjang akar tanaman miana pada 6 MST disajikan pada Tabel 2.

Pada Tabel 2 dapat dilihat bahwa pemberian zat pengatur tumbuh memberikan pengaruh pada jumlah akar. Panjang akar terendah pada 6 MST sebesar 16.00 $\mathrm{cm}$ didapat dari dari perlakuan control sedangkan panjang akar terbanyak didapat dari pemberian IAA sebesar 91 buah. Hal ini diduga karena IAA dengan konsentrasi yang sesuai dapat merangsang pembentukan akar pada tanaman secara maksimal. Hal ini didukung oleh Salisbury dan Ross (1995) yang menyatakan bahwa auksin merupakan suatu zat yang dapat mendorong pertumbuhan apabila diberikan pada konsentrasi yang tepat. Hal ini juga sesuai dengan fungsi auksin yaitu merangsang inisiasi akar dan mampu meningkatkan mobilisasi karbohidrat dari tunas sehingga mendorong aktivitas pertumbuhan akar. Davies (1995) menambahkan bahwa auksin sangat diperlukan dalam pembentukan akar yakni mampu merangsang inisiasi akar. Pengaruh berbagai zat pengatur tumbuh pada jumlah akar tanaman miana pada 6 MST disajikan pada Tabel 2.

Tabel 2. Pengaruh berbagai zat pengatur tumbuh pada panjang akar dan jumlah akar tanaman miana pada 6 MST

\begin{tabular}{|c|c|c|}
\hline Perlakuan & Panjang akar $(\mathrm{cm})$ & Jumlah akar (buah) \\
\hline Kontrol & $21.08 \mathrm{a}$ & $16.00 \mathrm{~b}$ \\
\hline Air Kelapa & $14.50 \mathrm{a}$ & $32.50 \mathrm{~b}$ \\
\hline IAA & $14.00 \mathrm{a}$ & $91.00 \mathrm{a}$ \\
\hline Growtone & $16.50 \mathrm{a}$ & $27.00 \mathrm{~b}$ \\
\hline
\end{tabular}

Keterangan : Angka yang diikuti notasi yang sama pada setiap kolom yang sama menunjukkan berbeda tidak nyata menurut Uji Jarak Berganda Duncan pada taraf $\alpha=5 \%$.

\section{Kesimpulan}

Berdasarkan hasil analisis data dan pembahasan pada penelitian ini maka dapat disimpulkan bahwa pemberian Zat Pengatur Tumbuh berpengaruh terhadap jumlah tunas dan jumlah akar. Jumlah tunas terbanyak terdapat pada perlakuan Growtone sebesar 7.50 tunas. Jumlah akar terbanyak terdapat pada perlakuan IAA sebesar 91.00 buah. Rekomendasi budidaya tanaman miana dengan cara stek dapat menggunakan IAA 750 ppm maupun Growtone 500 ppm.

\section{Ucapan Terima Kasih}

Penulis mengucapkan terimakasih kepada Laboratorium Agroekologi, Jurusan Agroekoteknologi, Fakultas Pertanian, Universitas Sultan Ageng Tirtayasa yang telah memberikan fasilitas sarana dan prasarana sehingga penelitian ini dapat terlaksana.

\section{Daftar Pustaka}

Arinasa, IBK, Sujarwo, W \& Peneng, IN (2015). The effect of Growtone concentrations and type of culm cuttings on growth of black petung bamboo (Dendrocalamus asper (Schult.) Backer ex Heyne 
cv. Black)', Bamboo Journal, Japan Bamboo Society, vol. 29, pp. 1-9.

Bawoleh, N. A., Yuda, I. P. \& L. Yulianti, I. M. (2017). Etnobotani tumbuhan pangan dan obat masyarakat suku arfak di Kampung Warmare, Kab. Manokwari. Universitas Atmajaya Yogyakarta. $15 \mathrm{hlm}$.

Davies, P.J. (1995). Plant Hormones. Kluwer Academic Publishers. Netherlands.

DPKP Malang kota (2017). http://dpkp.malang kota.go.id/2017/08/warna-warni-ceria-mianailer/. Diakses pada tanggal 11 Mei 9018.

Hartman HT, Kester DE, Davies Jr FT \& Geneve RL. (2002). Plant propagation: Principles and practices. 7th ed. Pearson Education INC., New Jersey

Hartmann, H. T, D. E. Kester \& f.T. Davies (1990). Plant Propagation and Practice. 5* Ed. Prentice Hall Intemational. New Jersey.

Hartmann, H. T. \& D. E. Kester. (1975). Plant Propagation Principle and 'Practices. London: Prentice Hall Inc.

Hartmann, H.T., D. E. Kester \& F. T. Davies Jr. (1990). Plant propagation, princples and pracies.Fithh edition.Prentice Hall, Inc. Engle Wood Cliff.New Jersey.578 p.

Haryati ES, F. Diba \& Wahdina (2015). Etnobotani tumbuhan berguna oleh masyarakat sekitar kawasan KPH model Kapuas Hulu. Jurnal Hutan Lestari 3 (3): 434-445.

Hidayat, Y. (2010). Pertumbuhan Akar Primer, Sekunder Dan Tersier Stek Batang Bibit Surian (Toona sinensis Roem) Wina Mukti Forestry research jurnal, 10 (2): 1- 8.

Lingga (1986). Petunjuk Penggunaan Pupuk. Penebar Swadaya. Jakarta. 163 hal

Pakadang \& Sesilia Rante (2015). Pengaruh Perbedaan Varietas Daun Miana (Coleus Scutellarioides [L.] Benth) Sebagai Antibakteri Terhadap Streptococcus pneumonia. Media Farmasi, XIV (23) : 113-117.
Salisbury, F.B \& C.W Ross. (1995). Fisiologi Tumbuhan Jilid 3. Penerbit Institut Teknologi Bandung. Bandung.

Shahab S, Ahmed N \& Khan NS. (2009). Indole acetic acid production and enhanced plant growth promotion by indigenous PSBs. African J Agric Res 4: 1312-1316.

Suswita D, Syamsuardi \& A. Arbain (2013). Studi etnobotani dan bentuk upaya pelestarian tumbuhan yang digunakna dalam upacara adat kendurisko di beberapa kecamatan di Kab. Kerinci, Jambi. Jurnal Biologika 2 (1): 67-80.

Uanikrishnan, K. \& J. P. Rajeeve. (1990). On germination of Indian teak (Tectonagrandis L.f.). Indian Forester. 102 (10): 650-658.

Wattimena, G.A. (1988). Zat Pengatur Tumbuh Tanaman. Laboratorium Kultur Jaringan. Tanaman PAU Bioteknologi IPB. Bogor. 145 hlm.

Wattimena, G.A. (2000). Pengembangan propagul kentang bermutu dan kultivar kentang unggul dalam mendukung peningkatan produksi kentang di Indonesia. Orasi Ilmiah Guru Besar Tetap Ilmu Horti-kultura. Fakultas Pertanian Institut Pertanian Bogor.

Wudianto, R. (2001). Membuat Stek, Cangkok dan Okulasi. Penebar Swadaya. Jakarta. 72 hal.

Zhao, Y. (2010). Auxin biosynthesis and its role in plant development. Ann Rev Plant Biol 61: 49-64. 